\title{
The Application of AHP Approach for Evaluating Location Selection Elements for Retail Store: A Case of Clothing Store
}

\author{
Mehmet Akalin ${ }^{\mathrm{a}}$, Gulden Turhan ${ }^{\mathrm{bi}}$, Azize Sahin ${ }^{\mathrm{c}}$ \\ ${ }^{a b}$ Professor, Department of Textile, Marmara University, Istanbul, Turkey \\ ${ }^{c}$ Department of Business Administration, Düzce University, Düzce, Turkey
}

\begin{abstract}
The aims of the study at using AHP (Analytic Hierarchy Process) are two-fold. First, the study aims to determine the relative importance or weight of multiple criteria and its attributes in the decision problem of location selection. The second aim of the study is to identify a location with the highest potential among alternatives for retailers by using a series of criteria and attributes determined. By the means of the AHP method, decision makers put weighted values to the evaluation criteria with respect to the related goal and the attributes with respect to the corresponding criteria. In addition, the priority weight for every location alternative on each criterion and attribute is estimated. The AHP process involves hierarchically structuring decision problem, setting priority weights, establishing a judgment matrix and weight vector, and then ranking the order of location alternatives. To substantiate the feasibility of this standard approach, a case study is conducted with location selection for a clothing store in this study.
\end{abstract}

Key Words: AHP; Relative Importance; Priority Weight; Location Selection; Criteria; Attributes; Alternatives; Clothing Store.

(C) 2013 Published by SSBFNET

\section{Introduction}

Store location selection is seen as one of the most crucial strategic decisions for retailers (Karande and Lombard 2005), since it is very often a determining factor in the performance of businesses. Indeed, there are other factors that affect the success or failure of retail stores, but adverse effects caused by the selection of a poor location are mostly the formidable or non-removable effects. Choosing the felicitous location can enable firms to increase their own store performance by making these stores more attractive for potential customers (Durvasula et al. 1992). Although their products remained unchanged, even small differences in settlements created by the retail outlets can spread quickly to the market, and thereby increasing market share and profitability (Karande and Lombard 2005). A new location

\footnotetext{
${ }^{i}$ Corresponding author.
} 
selection for an existing store or the establishment of a new shopping center is strategic decisions requiring a longterm investment (Ingene and Lusch 1980; Craig, Ghosh and McLafferty 1984). If a good choice of location cannot be performed, firms will suffer financially because the cost of replacing it with a new location is very high (Durvasula, Sharma and Andrews 1992). As a result of an unsuccessful choice of location, they may be faced with a risk of damaging their store image (Pope, Lane and Stein 2012). For these reasons, making a right decision in store location selection is very important for retailers.

Choice of store settlement area is a decision problem needed to identify the best option among alternatives by taking into account a large number of criteria. AHP method is used in the process of forming the solution to this multi-criteria decision problem which incorporates various store-location selection parameters, such as population, retail settlement, cost and competition and the relative sub-criteria or attributes. As one of the multi-criteria decision making methods, AHP approach has been more widely accepted as valid in literature for analyzing and solving great numbers of problems in various fields of decision making, for instance finance, marketing, education, public policy, economics, commerce, health, sports etc. (Timor and Sipahi 2005). Apparently, there has been a limited attempt to apply this method to the problem of store location selection in marketing and/or retailing literature. Out of the studies executed for clothing retailers, the almost all of them are intensely centered on site selection instead of location selection. The current research intents to extend the application area of AHP method by handling it in evaluating location selection of clothing store.

The organization of this paper is as follows. First, we review the evaluation elements to this research. Next, the details of the proposed methodology are presented. It's followed by the application of AHP to the case of clothing store. Finally, the evaluation of location selection criteria and alternatives are discussed through an example application. Herein, the final report is organized in line with the results, in which the solution to the decision problem of location selection is presented.

\section{Location Selection Criteria and Attributes}

According to literature survey, the criteria which are effective on location selection decision for the retail stores have been handled by a number of researchers. There are a wide range of criteria that guide retailers to evaluate their location decisions. In this study, Figure 2 provides us with hierarchically representation of criteria which are important for the retail store's location selection. In line with the experts' point of view, we have decided to collect these location selection criteria into four groups: (1) population (2) retail settlement (3) costs and (4) competition.

To make the choice of good store locations, population structure has been examined in many previous studies by dealing with the following attributes: (i) the amount of money that people are willing to spend for buying the retailers' goods, (ii) population's growth rate, and (iii) coherent target market in terms of demographics such as gender, education, age, occupation and the like. In Redinbaugh's book (1987), the issue of retail location selection has been interpreted in detail. In the book, it seems that in searching for good locations, retailers desire to reach people who are 
willing to spend money for buying their goods. Because the rate of retail expenditures per people (or household) are expected to increase by a rise in population density (Ingene and Lusch 1980), another valuable aid for estimation of the market area in which to locate is viewed as population growth rate (Irwing 1986:256; Kuo et al. 2002; Berman and Evans 2010:266). In addition, retailers are in search of coherent target market for the eventual success of any one location. Demography provides the knowledge for understanding if the population residing in the location that retailer decides to serve is coherent with its target market (Hasty and Reardon 1997:207; Berman and Evans 2010:263).

The most commonly used attributes to identify retail settlement in the location selection decisions are (i) ease in accessibility, (ii) parking facilities, and (iii) located at a street corner (or road intersection). 'Ease in accessibility' refers to the people's ability not only to find the store easily and quickly (Dune and Lusch 2008:205), but also to get into and out of it (Levy and Weitz 1998:247). Given the scarcity of time caused by changes in life styles and life cycles, e.g. increasing number of women in the workforce (Brown and McEnally 1993), people value quick-and-easy shopping excursions (Seiders et al., 2000). Many customers shop by automobile, thus adequate parking facilities must also be provided (Redinbaugh 1987:188; Irwing 1986:257) to make easier their access to the shopping area. In addition, located at road intersection could allow for good visibility. According to the researcher Levy and Weitz (1998), visibility refers to customers' ability to see the store. 'In an area with transient population, good visibility from the road is particularly important.' (Levy and Weitz 1998:247).

In their quest for locations, retailers must study costs possibilities for expansion or entering into the market. The storelocation selection decision involve such various costs as (i) building and/or renovating (ii) buying or renting and (iii) transportation and/ or warehousing costs of the physical store (Irwing 1986:257). Other researchers (i.e. Berman and Evans 2010:265) also announced that retailers should deal with costs as evaluation criteria when searching for a promising location.

Retailers also need to account for competition effects of an area where store is located. Previous research proposed some competitive variables: (i) competitors' store numbers (Kuo et al. 2002; Li and Liu 2012), (ii) the spatial proximity to competitors (Karande and Lombard 2005; Li and Liu 2012), (iii) travel time and (iv) closeness to culture, amusement and relaxation centers. When a set of store alternatives in shopping are available in an area, consumers are by no means restricted by purchasing from only one store since they can visit several other stores there (Karande and Lombard 2005). Therefore, the number of stores in a market where to be entered is very important for retailers in attempting to entice the consumer to buy more their goods. Besides, Li and Liu (2012) explained that purchase incidence varies by depending upon the spatial proximity to competitors. They also proposed that the probability of patronizing a certain shopping area is inversely related to its distance from the consumer (i.e. travel time). As such, all retailers should consider the presence of magnet stores (i.e. culture, amusement and relaxation centers) as an advantage since the stores attract more trade from greater distances (Timmermans 1986). 


\section{Analytical Hierarchy Process (AHP) Method}

AHP was a method advanced by Saaty $(1980,1982)$ for use in solving multi-criteria decision problems (Timor and Sipahi 2005). Effectively handle both qualitative and quantitative data is an advantageous aspect of this method (Kuo et al. 2002; Timor and Sipahi 2005). In assessing complex decision problems, especially involving subjective judgment (Timor and Sipahi 2005; Lin et al. 2009), AHP helps decision makers understand the structure of the decision making model by making the problems easier to be understood (Wang et al. 2004). With AHP, a complex problem is seperated into multi-level hierarchical structure of goals, criteria, attributes and alternatives (Saaty 1990; Triantaphyllou and Mann 1995:35; Wang et al. 2004). The application of AHP method consists of seven basic steps mentioned below (see also Figure 1).

\subsection{Describing the Decision Problem}

The first step is to review the related studies in literature and interview with experts (Kuo et al. 2002) in order to describe the decision problem with multiple criteria and attributes used for its solution.

\subsection{Developing the Hierarchical Structure of Decision Problem}

The problem is decomposed into its criteria of which every possible attributes (sub-criteria) are arranged into multiple hierarchical levels (Ho 2008). Each criterion is further separated into its own attributes that are grouped together at the same level (Saaty 1994; Mikhailov and Tsvetinov 2004; Timor and Sipahi 2005). The top level of hierachy represents the goal (or problem) in decision making process. The next level involves a serious of decision criteria used for solving the related problem. Following that, attributes are listed under the respective decision criteria (Kuo et al. 2002).

\subsection{Setting the Priority Weight of the Elements by Pair-Wise Comparisons}

The aim of pair-wise comparison is to determine the priority weights of elements (criteria, attributes and alternatives) at each level of the hierarchy (Timor and Sipahi 2005). Decision makers compare all elements in the same level in pairs in terms of their priority weight based on their own experience and knowledge (Ho et al. 2013). "For instance, every two criteria in the second level are compared at each time with respect to the goal, while every two attributes of the same criterion in the third level are compared at a time with respect to the corresponding criterion" (Ho 2008). In addition, for each pairing among themselves, the alternatives in the lowest level of hierarchy are compared at every turn not only in respect to the criterion but also in respect to the attribute. With the aiming to determine the related weights, decision makers are conducted via a survey questionnaire designed in the form of pairwise comparison matrix for each pairing within the hierarchical framework. A rating scale is used to measure the weight of every element in pair-wise comparison. 


\subsection{Calculating Priority Weights for Every Element in Each Level}

After doing pair-wise comparisons, a weight value for each element (i.e. criterion, attribute or alternative) is assigned to the more important one whereas the reciprocal of this value is assigned to the other one in the pair. For each pairing of elements, the better option is awarded as a score, whilst the scoring of other option in the pairing is subject to the reciprocal of this value. The weightings are then normalized and averaged in order to calculate a relative weight for every element (criterion, attribute, or alternative) (Kasperczyk and Knickel 2013).

\subsection{Consistency Check}

Consistency ration (CR) is calculated to verify the credibility of decision makers' judgments obtained by pairwise comparison (Yang and Kuo 2003; Yun 2004). If the value of the CR should be 0.1 or less, then the pair-wise

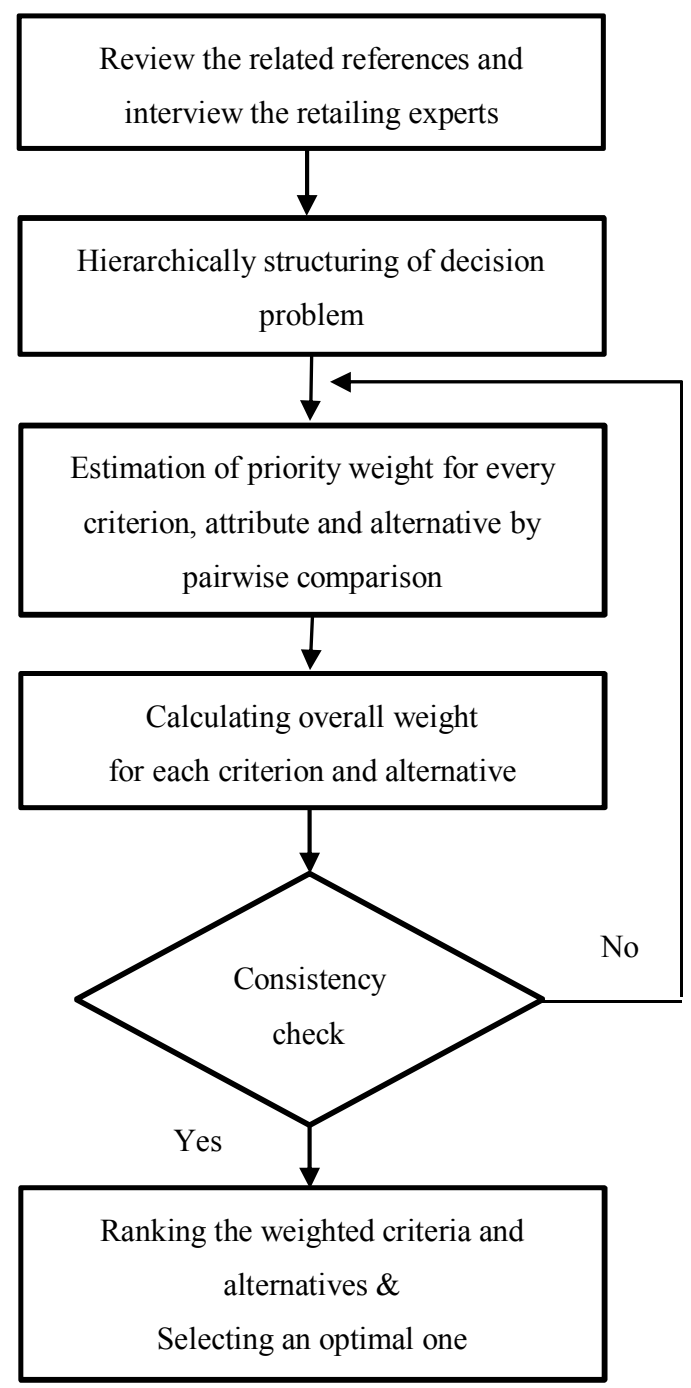

Fig 1. AHP Application Procedure 


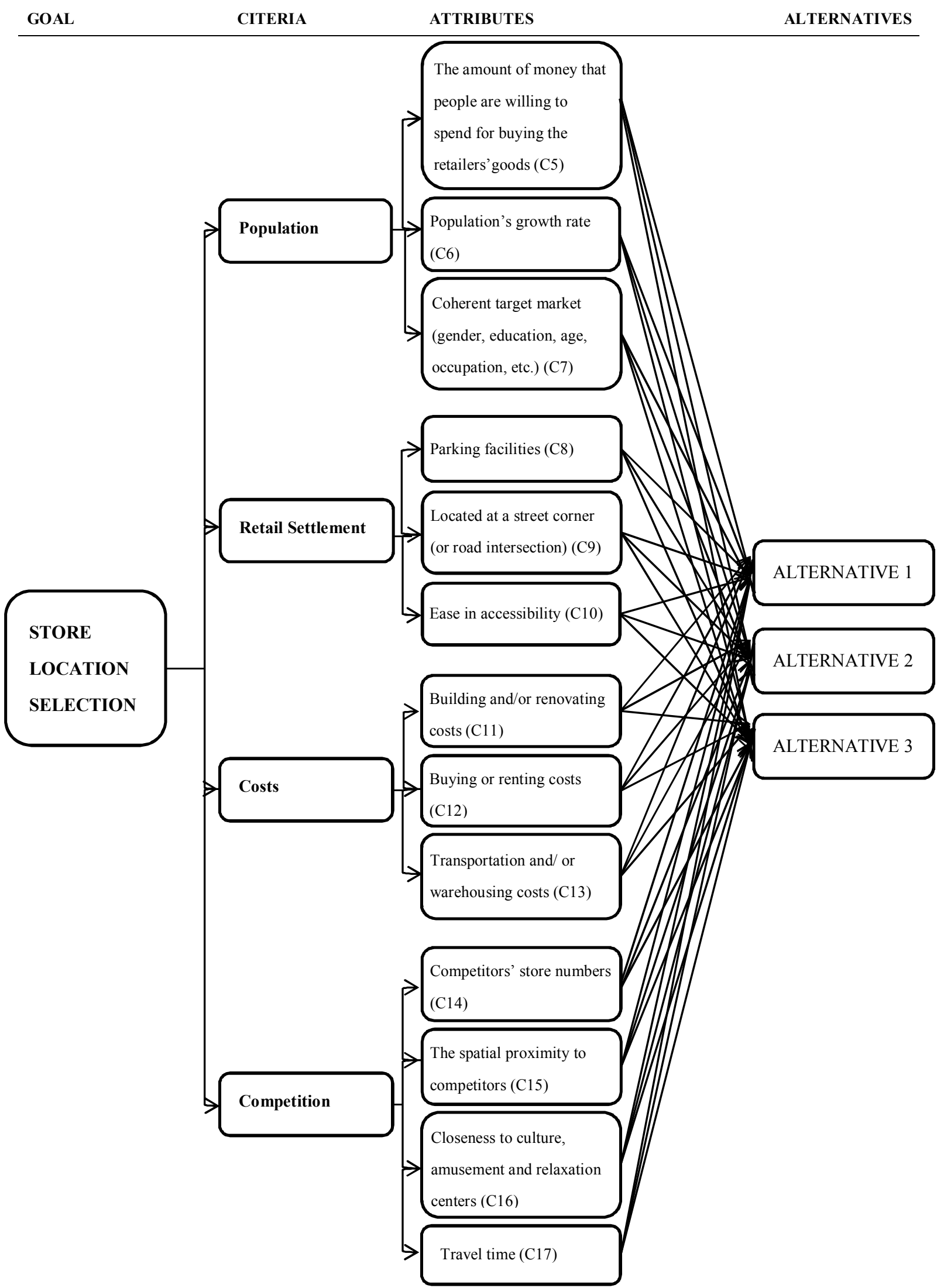

Fig. 2. The Hierarchical Structure of Store Location Selection 
comparisions are considered as having an acceptable consistency. If, however, the value goes over 0.1 , then the values of the ratio are indicative of inconsistent judgements, in which the result is not reliable (Chen 2006).

\subsection{Ranking and Selecting an Optimal Element}

The last step of the AHP aggregates all relative weights that express the relative impact of the set of elements on an element in the level generated by use of the set of pairwise comparison matrices. Herein, "global weights for each element (i.e. attribute or alternative) are synthesized from the second level down by multiplying the relative weights by the corresponding criterion (or alternative) in the level above and adding them for each element in a level according to the criteria (alternative) it affects." As a result, the global priorities obtained are used for final ranking of the criteria, attributes and alternatives, and selection of the best one for each.

\section{The Mathematics of AHP}

\section{Step 1. Pair-wise comparison}

The elements of each level are compared in a pairwise fashion with respect to the next upper level element in terms of their importance. Moving from the top to the bottom of the hierarchy, the pairwise comparisons at a given level can be reduced to multiple square matrices $C=\left[C_{i j}\right]_{n x n}$ as is the following:

$\left[\begin{array}{lll}C_{11} & C_{12} & C_{13} \\ C_{21} & C_{22} & C_{23} \\ C_{31} & C_{32} & C_{33}\end{array}\right]$

The matrix which has reciprocal properties $R=\left[\frac{1}{C_{i j}}\right]_{n x n}$ are represented as

$$
\left[\begin{array}{ccc}
\frac{1}{C_{11}} & \frac{1}{C_{12}} & \frac{1}{C_{13}} \\
\frac{1}{C_{21}} & \frac{1}{C_{22}} & \frac{1}{C_{23}} \\
\frac{1}{C_{31}} & \frac{1}{C_{32}} & \frac{1}{C_{33}}
\end{array}\right]
$$

In AHP, as suggested Satty (1980), a scale of relative importance from 1 to 9 is used to make subjective pairwise comparisons (see Table 1). First, all pairwise comparison matrices are formed. Then, the vector of weights, $W=$ $\left[W_{1}, W_{2}, \ldots, W_{n}\right]$, is computed on the basis of Satty's eigenvector procedure. The calculation of the weights involves two steps: (1) forming a normalized pair-wise matrix and (2) creating weighted matrix (Chen 2006). The scale of the relative importance is defined in Table 1 according to Satty 1-9 scale for pairwise comparison. 
Table 1: 9-point intensity of relative weight (importance or well-being) scale

\begin{tabular}{|c|c|c|}
\hline Intensity of importance/well-being & Definition & Significance \\
\hline 1 & $\begin{array}{l}\text { Equal importance } \\
\text { /Equally good }\end{array}$ & Two activities contribute equally to objective. \\
\hline 3 & $\begin{array}{l}\text { Moderate importance of one factor over } \\
\text { another } \\
\text { / Weakly }\end{array}$ & $\begin{array}{l}\text { Experience and judgment slightly favor one } \\
\text { activity over another. }\end{array}$ \\
\hline 5 & $\begin{array}{l}\text { Strong or essential importance } \\
\text { / Strongly }\end{array}$ & $\begin{array}{l}\text { Experience and judgment strongly favor one } \\
\text { activity over another. }\end{array}$ \\
\hline 7 & $\begin{array}{l}\text { Very strong importance } \\
\text { / Very strongly }\end{array}$ & $\begin{array}{l}\text { An activity is strongly favored, and its dominance } \\
\text { is demonstrated in practice. }\end{array}$ \\
\hline 9 & $\begin{array}{l}\text { Extreme importance } \\
\text { / Absolutely better }\end{array}$ & $\begin{array}{l}\text { The evidence favoring one activity over another is } \\
\text { of the highest possible order of affirmation. }\end{array}$ \\
\hline $2,4,6,8$ & $\begin{array}{l}\text { Intermediate value between the two } \\
\text { adjacent judgments }\end{array}$ & When a compromise is needed. \\
\hline $\begin{array}{l}\text { Reciprocals of the above nonzero } \\
\text { numbers }\end{array}$ & Reciprocals for inverse comparison & \\
\hline
\end{tabular}

Source: Adapted from Satty (1982, p.78); Satty and Kearns (1985); Timor and Seyhan (2005); Chen (2006).

\section{Step 2. Normalization}

The pair-wise comparison matrix, $C=\left[C_{i j}\right]_{n x n}$, is normalized by equation (1) (Chen 2006), in which each element in the matrix is divided by its column total to generate a normalized pair-wise matrix (Bunruamkaew 2012).

$X_{i j}=\frac{C_{i j}}{\sum_{i=1}^{n} c_{i j}}\left[\begin{array}{lll}X_{11} & X_{12} & X_{13} \\ X_{21} & X_{22} & X_{23} \\ X_{31} & X_{32} & X_{33}\end{array}\right]$

for all $\mathrm{j}=1,2, \ldots, \mathrm{n}$.

\section{Step 3. Weight calculation}

The weights are computed by equation (2), in which the sum of the normalized column of matrix is divided by the number of criteria used (n) to generate weighted matrix (Bunruamkaew 2012).

$W_{i j}=\frac{\sum_{j=1}^{n} X_{i j}}{n}\left[\begin{array}{l}W_{11} \\ W_{12} \\ W_{13}\end{array}\right]$

for all $\mathrm{i}=1,2, \ldots, \mathrm{n}$

Step 4. Consistency check

In order to obtain consistency vector, the pair-wise matrix is multiplied by the weights vector; that is, 
$\left[\begin{array}{lll}C_{11} & C_{12} & C_{13} \\ C_{21} & C_{22} & C_{23} \\ C_{31} & C_{32} & C_{33}\end{array}\right] *\left[\begin{array}{l}W_{11} \\ W_{21} \\ W_{31}\end{array}\right]=\left[\begin{array}{l}C_{11} \\ C_{21} \\ C_{31}\end{array}\right]$

Then, it is achieved by dividing the weighted sum vector with criterion weight (Bunruamkaew 2012).

$$
\begin{aligned}
& C v_{11}=\frac{1}{W_{11}}\left[C_{11} W_{11}+C_{12} W_{21}+C_{13} W_{31}\right] \\
& C v_{21}=\frac{1}{W_{21}}\left[C_{21} W_{11}+C_{22} W_{21}+C_{23} W_{31}\right] \\
& C v_{31}=\frac{1}{W_{31}}\left[C_{31} W_{11}+C_{32} W_{21}+C_{33} W_{31}\right]
\end{aligned}
$$

There is a relationship between the vector weights, $W$, and the pairwise comparison matrix, $C$, as shown in the following equation (5) (Chen 2006).

$C_{W}=\lambda_{\max } W$

The value of $\lambda_{\max }$, the maximum eigenvalue of the comparison matrix (Mikhailov and Tsvetinov 2004), is an important validating parameter in AHP. It is used as a reference index to screen information by calculating the consistency ratio (CR) of the estimated vector (Chen 2006). $\lambda$ is obtained by averaging the value of the consistency vector, formulated using equation (6) (Bunruamkaew 2012).

$\lambda=\sum_{i=1}^{n} C v_{i j}$

In order to calculate the $\mathrm{CR}$, the consistency index (CI) for each matrix of order $n$ can be obtained from equation (7) (Chen, 2006).

$C I=\frac{\lambda_{\max }-n}{n-1}$

Then, CR, the ratio of $\mathrm{CI}$ and RI, is given by the formula (8):

$C R=\frac{C I}{R I}$

where $R I$ is the random consistency index obtained from a randomly generated pairwise comparison matrix. Table 2 shows the values of the RI for matrices of order 1 to 15 (Satty 1980). Any higher value at any level (RI>.01) indicates that the decison makers' judgements warrant re-examination (Bunruamkaew 2012), thus AHP procedure should be reviewed and revised by starting from the 3rd step (Fig. 1) (Chen 2006). 
Table 2: Random index for $\mathrm{N}=15$

Random index (RI)

\begin{tabular}{|c|c|c|c|c|c|c|c|c|c|c|c|c|c|c|c|}
\hline $\mathrm{N}$ & 1 & 2 & 3 & 4 & 5 & 6 & 7 & 8 & 9 & 10 & 11 & 12 & 13 & 14 & 15 \\
\hline RI & 0.00 & 0.00 & 0.58 & 0.90 & 1.12 & 1.24 & 1.32 & 1.41 & 1.45 & 1.49 & 1.51 & 1.48 & 1.56 & 1.57 & 1.58 \\
\hline
\end{tabular}

Source: Satty 1980

Step 5. Aggregate the assessments of multiple decision makers

In order to create an aggregate measure of the pairwise comparisons of all individuals involved in a decision problem, the individual assessments are averaged using equation (9)

$c_{i j}^{h p}=\sqrt[q]{\prod_{q=1}^{q} c_{i j}^{q}}$

where $c_{i j}^{q}$ is an element of matrix $C$ of an individual $q(q=1,2,3, \ldots, Q)$, and $c_{i j}^{h p}$ is the arithmetic mean of all individuals $c_{i j}^{q}$. The group $C R$ is calculated according to equations (7) and (8) (Satty 1989; Chen 2006).

\section{Case Application}

In the retail context, AHP is applied to obtain the weights on each of location selection criteria and attributes to prioritize performance of alternatives. The solution to find suitable location from many alternatives is developed by using AHP method. For this purpose, the steps of AHP procedure shown in Fig. 1 are followed.

\subsection{Developing the Evaluation Hierarchy}

The criteria are decided to be used to evaluate location alternatives by utilizing from the related paper and knowledge of domain experts. There exist many criteria that influence location decisions of retailers. But, some criteria are considered so important that they are indispensable factors in order to evaluate many location alternatives effectively. The following criteria are, in this study, taken into account for evaluating three potential locations in which are considered to settle; population (C1), retail settlement (C2), costs (C3) and competition (C4). Each is decomposed into its own attributes. Firstly, the attributes of the criterion 'population' include the amount of money that people are willing to spend for buying the retailers' goods (C5), population's growth rate (C6), and coherent target market (C7). Second, the attributes of the criterion 'retail settlement' are parking facilities (C8), composed of located at a street corner (or road intersection) (C9) and ease in accessibility (C10). Next, the attributes of the criterion 'costs' are following as: building and/or renovation costs (C11), buying or renting costs (C12) and transportation and/or warehousing costs (C13). Finally, the attributes of the criterion "competition" contain competitors' store numbers (C14), the spatial proximity to competitors (C15), closeness to culture, amusement and relaxation centers (C16) and travel time (C17). 
In Fig. 2, the hierarchy of research problem or goal is structured by decomposing its criteria, attributes and alternatives. Research problem, in this study, is the selection decision of optimal location from three alternatives proposed for a clothing store (Level 1). Level 2 is composed of four fundamental criteria necessary to be considered while retailers make a decision regarding where to locate a store. A total of fifteen attributes (sub-criteria) from Level 3 are attributed to these criteria. Lastly, three possible alternatives are listed at the lowest level (Level 4).

\subsection{Questionnaire Survey}

A questionnaire survey was designed for collecting data of pairwise comparisons. To determine priority weight of every criterion, attribute and alternative in the problem of location selection, each is compared with others in a pairwise fashion. Herein, these weights represent decision makers' perceived importance of each criterion and attribute (Min 2010). That is, for each pair of criteria or attributes the decision maker is asked to respond to a question such as 'How important is criterion X relative to criterion Y?', as can be seen in Table 1. As for the weights in pairwise comparisons of alternatives, they show 'How well alternative A meets criterion B?' for respondents, shown in Table 2 (Kasperczyk and Knickel 2013). As a data collection tool, the questionnaire is constructed according to pairwise comparison matrix. Five different degree of evaluation are used to measure decision makers' judgments about the weight of selection criteria and attributes, as recommended by Saaty (1980), namely: 1- equally important, 2 moderately important, 3- strongly important, 4- very strong important and 5- extremely important. On the one hand, respondents' assessments regarding the weight of alternatives are recorded by a scale ranging from 1(equally good) to 5 (absolutely better) (Kasperczyk and Knickel 2013).

\subsection{Data Collection}

An expert, who is a decision maker for the selection of store location, is conducted by face-to-face interviews. The decision maker is working as the store manager of a clothing store and he has six years' experience on the job. Through the interview, data is collected via the questionnaire forms prepared in accordance with the AHP method. Pair wise comparisons are applied to all factors or element with respect to their corresponding level. And then, priority weights among the elements in the hierarchy are established. All the evaluation factors (criteria or attributes) and their corresponding weights are presented in Appendix.

\subsection{Synthesis of Priority Weights}

The priority weight of criteria and attribute is calculated using the eigenvector method aforementioned (see tables from A1 to A5 in the appendix). First, a pairwise comparison matrix is developed for each criterion, and then the resulting matrix is normalized to unify the result. To get priority of a single criteria (or attribute, or alternative)relative weights-, pairwise comparisons are aggregated by averaging the corresponding values. 


\subsection{Results of Consistency Test}

Consistency ratio for the expert's judgments was calculated and checked. In Table 3, the results reveal that all CR value are lower than .01 , thus the consistency of all the judgments are satisfactory.

Table 3: Consistency test for location selection goal, criteria and attributes

\begin{tabular}{llcc}
\hline Level & & Consistency Ratio & Consistency Test \\
\hline $\begin{array}{llll}\text { Goal } \\
\text { Criteria }\end{array}$ & & 0.041 & Accepted \\
& - Population (C1) & 0.000 & Accepted \\
& - Retail Settlement (C2) & 0.000 & Accepted \\
& Costs (C3) & 0.001 & Accepted \\
& - Competition (C4) & 0.044 & Accepted \\
\hline
\end{tabular}

\subsection{Obtaining the Final Ranking and Choosing an Optimal Element}

Table 4 summarizes relative and global weights for each criterion and attribute in store location selection, along with their ranking. the global weights to use in ranking of elements are calculated by multiplying relative weights observed for each sub-element (i.e. attribute) and the corresponding upper-element (i.e. criteria). Then, we put them in order from largest to smallest based on what is the priority weight of each element (i.e. attribute). An optimal element (i.e. attribute) that has highest score in a priority rating is selected, based on their corresponding global weights. The relative and global weights of location alternatives and its priority order are shown in Table 5. Herein, 3 alternative locations are evaluated by using weighted average sum method in terms of a number of decision elements (criteria and

Table 4: Relative and global weights for each criterion and attribute in store location selection

\begin{tabular}{|c|c|c|c|c|c|}
\hline Criterion & $\begin{array}{l}\text { Relative } \\
\text { weight }\end{array}$ & Attribute & $\begin{array}{l}\text { Relative } \\
\text { weight }^{\text {a }}\end{array}$ & $\begin{array}{c}\text { Global } \\
\text { weight }\end{array}$ & Ranking \\
\hline \multirow[t]{4}{*}{ Population $(\mathrm{C} 1)$} & 0.526 & & & & \\
\hline & & $\begin{array}{l}\text { The amount of money that people are willing to spend for } \\
\text { buying the retailers' goods (C5) }\end{array}$ & 0.214 & 0.113 & 3 \\
\hline & & - $\quad$ Population growth rate $(\mathrm{C} 6)$ & 0.107 & 0.056 & 5 \\
\hline & & $\begin{array}{l}\text { - Coherent target market (gender, education, age, occupation } \\
\text { etc.) (C7) }\end{array}$ & 0.429 & 0.226 & 1 \\
\hline \multirow[t]{4}{*}{$\begin{array}{l}\text { Retail Settlement } \\
\text { (C2) }\end{array}$} & 0.124 & & & & \\
\hline & & - $\quad$ Parking facilities (C8) & 0.107 & 0.013 & 10 \\
\hline & & - Corner location or located near road intersection (C9) & 0.420 & 0.052 & 6 \\
\hline & & - $\quad$ Ease in accessibility $(\mathrm{C} 10)$ & 0.214 & 0.026 & 9 \\
\hline \multirow[t]{4}{*}{ Costs (C3) } & 0.077 & & & & \\
\hline & & - $\quad$ Building and/or renovating costs $(\mathrm{C} 11)$ & 0.172 & 0.013 & 10 \\
\hline & & - $\quad$ Buying or renting costs $(\mathrm{C} 12)$ & 0.486 & 0.037 & 7 \\
\hline & & - Transportation and/ or warehousing costs $(\mathrm{C} 13)$ & 0.092 & 0.007 & 11 \\
\hline \multirow[t]{5}{*}{ Competition (C4) } & 0.272 & & & & \\
\hline & & - Competitors' store numbers (C14) & 0.450 & 0.122 & 2 \\
\hline & & The spatial proximity to competitors $(\mathrm{C} 15)$ & 0.300 & 0.082 & 4 \\
\hline & & - Closeness to culture, amusement and relaxation centers (C16) & 0.099 & 0.027 & 8 \\
\hline & & - $\quad$ Travel time $(\mathrm{C} 17)$ & 0.300 & 0.082 & 4 \\
\hline
\end{tabular}

a. Relative weight is derived from judgment with respect to a single criterion (or attribute).

b. Global weight is derived from multiplication by the weight of the attributes by the corresponding criteria. 
Table 5: Relative and global weights for each alternative in terms of store selection elements

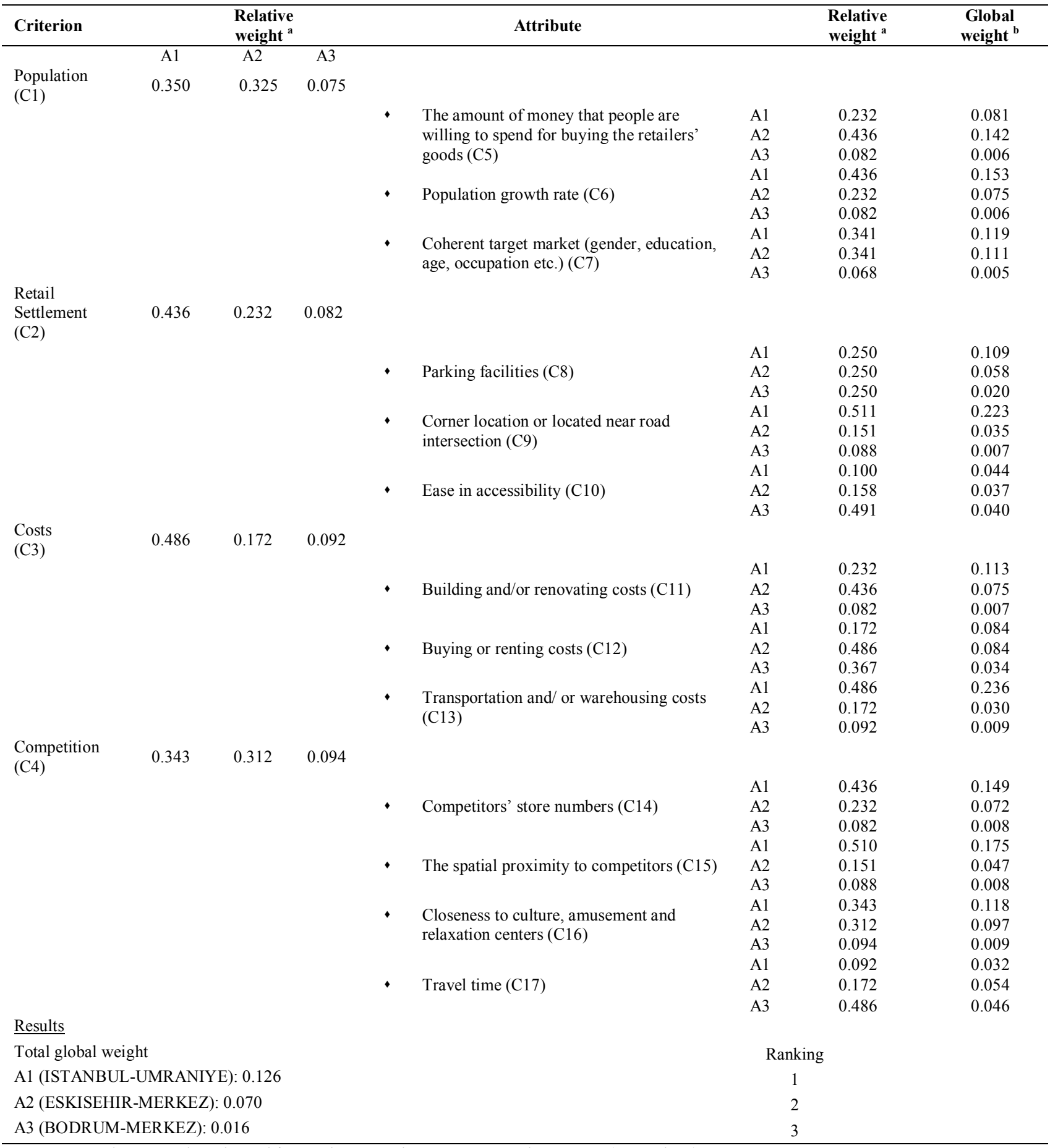

a. Relative weight is derived from judgment with respect to a single criterion (or attribute).

b. Global weight is derived from multiplication by the weight of the attributes by the corresponding criteria.

attributes). Scores are developed from the performance of alternatives with respect to individual elements (i.e. attribute). As mentioned-above, the global weights for each attribute are first evaluated as the multiplication result of 
the relative weights of attribute and the corresponding criteria. And, the values are then aggregated into an overall score by averaging the summation of relative weights at each attribute level in order to rank these alternatives.

\section{Results}

The evaluation of store-location selection criteria in Table 4 indicates that 'Population' (\%52.6) is considered as the most important factor or criterion. Following important criteria are 'Competition' (\%27.2), 'Retail Settlement' (\%12.4) and 'Costs' (\%7.7). According to the global weights, the most important attribute is (1) Coherent target market (\% 22.6). Other important attributes in order of their priorities are (2) Competitors' store numbers (\%12.2), (3) The amount of money that people are willing to spend for buying the retailers' goods (\%11.3), (4) the attribute 'The spatial proximity to competitors' and 'travel time' -sharing equal weights- (\% 8.2), (5) Population growth rate (\%5.6), (6) Corner location or located near road intersection (\%5.2), (7) Buying or renting costs (\%3.7), (8) Closeness to culture, amusement and relaxation centers (\%2.7), (9) Ease in accessibility (\%2.6), (10) the attribute 'Parking facilities' and 'Building and/or renovating costs' with equal weights (\%1.3), (11) Transportation and/ or warehousing costs $(\% 0.7)$.

The relative weight of the all criteria is at highest for the first alternative (A1) with $\% 35$ for the criterion 'Population', $\% 43.6$ for 'Retail settlement', \% 48.6 for 'Costs' and \% 34.3 for 'Competition'. The second highest value is observed for the second alternative (A2) on the aforesaid all criteria with $\% 32.5, \% 23.2, \% 17.2$ and $\% 31.2$, in turn. Such as, the lowest value belongs to the rest alternative (A3) for all the same criteria with \% 7.5, \% 8.2, \% 9.2 and \% 9.4. When alternatives are evaluated by using the priority weights of sub-criteria (i.e. attributes), in Table 5 , the results show that alternative A2 with the percent of 12.6 (ESKISEHIR-MERKEZ) performs better than alternative A1 with the percent of 7 (ISTANBUL-UMRANIYE): on all factors. It's followed by A3 with the percent of 1.6 (BODRUM-MERKEZ).

\section{Conclusion}

In this study, aiming to solve the store-location selection problem for a clothing store, AHP was performed to determine an appropriate location that is better complied with the preference of retailers' under their own needs. The evaluation weights provided by AHP can be applied as a way to select important evaluation factors (criteria and attributes), and well-being alternatives. This can help store managers to develop a suitable solution for their store location selection decision by allowing them to structure the relative evaluation factors into priority weights, which can reflect their own priority considerations.

The proposed evaluation model by this study demonstrates that the criteria 'Population' and 'Competition' reveal their dominating importance. The criteria 'Retail settlement' and 'Costs' are coming in the next order. Decision maker's judgments show that location selection for a clothing store requires enormous attention to the attributes 'Coherent target market', 'Competitors' store numbers', 'The amount of money that people are willing to spend for buying the retailers' goods' and some others. Decision maker's first preference for the location of a clothing store should be the 
alternative 2 that is the center of ESKISEHIR in Turkey. Obviously this preference will show better performance than other options in terms of the relative criteria and attributes.

In this study, we have intended to show an expert's point of view for "important store-location selection factors". AHP is used in order to calculate the weights of the factors, which is considered as being important by a decision maker in evaluating location selection of clothing store. In the future, we can apply the proposed location selection model with a bunch of criteria or attributes to different types of line, like amusement center (e.g. PlayStation café) or sport center. And, alternatives can be evaluated again using AHP.

\section{ACKNOWLEDGEMENTS}

This study was supported by a grant from Marmara University BAPKO Research Project Committee

\section{References}

Brown, L. G. and McEnally, M. R. (1993). Convenience: Definition, structure and application. Journal of Marketing Management, 2, 2, 47-56.

Bunruamkaew, K. (2012). How to do AHP analysis in Excel division of spatial information science graduate school of life and environmental sciences university of Tsukuba, (Retrieved March 17, 2013, from the site: http://giswin.geo.tsukuba.ac.jp/sis/gis_seminar/How\%20to\%20do\%20AHP\%20analysis\%20in\%20Excel.pdf)

Chen, C. (2006). Applying the analytical hierarchy process (AHP) approach to convention site selection. Journal of Travel Research, 45, 167-174.

Craig, C. S.; Ghosh, A. and McLafferty, S. (1984). Models of the retail location process: A review. Journal of Retailing, 60, 1, 5-36.

Dune, P. M. and Lusch, R. F. (2008). Retailing, 6th ed., Thomson Coorporation: China.

Durvasula, S.; Sharma, S. and Andrews, J. C. (1992). Storeloc: A retail store location model based on managerial judgments. Journal of Retailing, 68, 4, 420-444.

Hasty, R. and Reardon, J. (1997). Retail management: Mcgraw-Hill Compnay, Inc., USA: McGraw-Hill, ISBN 0-07027031-7.

Ho, H.; Chang, C. and Ku, C. (2013). On the location selection problem using analytic hierarchy process and multichoice goal programming. International Journal of Systems Science, 44, 1, 94-108.

Ho, W. (2008). Integrated analytic hierarchy process and its applications - A literature review. European Journal of Operational Research, 186, 211-228.

Ingene, C. A. and Lusch, R. F. (1980). Market selection decesions for department stores. Journal of Retailing, 56, 3, $21-40$.

Irwing, B. (1986). Basic retailing. Irwin, Inc. Illinois, USA.

Karande, K. and Lombard, J. R. (2005). Location strategies of broad-line retailers: an empirical investigation. Journal of Business Research, 58, 687-695. 
Kasperczyk, N. and Knickel, K. (Retrieved March 17, 2013, from the site: http://www.ivm.vu.nl/en/Images/MCA3_tcm53-161529.pdf)

Ko, Y. and Kuo, P. (2010). Fuzzy logic-based evaluation method for idea screening of product design. Proceedings of the 2010 IEEE IEEM, 1004-1008.

Kuo, R. J.; Chi, S. C. and Kao, S. S. (2002). A decision support system for selecting convenience store location through integration of fuzzy AHP and artificial neural network. Computers in Industry, 47, 199-214.

Levy, M. and Weitz, B. A. (1998). Retailing management. ( $3^{\text {rd }}$ ed.). Irwin, McGraw-Hill Companies Inc.: US.

Lin, H.; Lee, H. and Wang, D. W. (2009). Evaluation of factors influencing knowledge sharing based on a fuzzy AHP approach. Journal of Information Science, 35, 1, 25-44.

Mikhailov, L. and Tsvetinov, P. (2004). Evaluation of services using a fuzzy analytic hierarchy process. Applied Soft Computing, 5, 23-33.

Min, H. (2010). Evaluating the comparative service quality of supermarkets using the analytic hierarchy process. Journal of Services Marketing, 24/4, 283-293.

Pope, J. A.; Lane, W. R. and Stein, J. (2012). A multiple-attribute decision model for retail store location. Southern Business Review, 15-25.

Redinbaugh, L. D. (1987). Retailing management: A planning approach. McGraw-Hill, Inc.

Saaty, T. L. (1980). The analytical hierarchy process: Planning, priority setting, resource allocation. New York: McGraw-Hill.

Saaty, T. L. (1982). Decision making for leaders. Newyork: Lifetime Learning.

Saaty, T. L. (1990). An exposition of the AHP in reply to the paper remarks on the analytic hierarchy process. Management Science, 36, 3, 259-268.

Saaty, T. L. and Vargas, L. G. (1991). Prediction, projection and forecasting. Kluwer Academic Publishers, 251 pp., Dordrecht.

Seiders, K.; Berry, L. L. and Gresham, L. G. (2000). Attention, retailers! How convenient is your convenience strategy? Sloan Management Review, 43, 3, 79-89.

Timmermans, H. (1986). Locational choice behavior of entrepreneurs: an experimental analysis. Urban Studies, 7, 3, 231-240.

Timor, M. and Sipahi, S. (2005). Fast-food restaurant site selection factor evaluation by the analytic hierarchy process. The Business Review, Cambridge; 4, 1, 161-167.

Triantaphyllou, E. and Mann, S. H. (1995). Using the analytic hierarchy process for decision making in engineering applications: Some challenges. International Journal of Industrial Engineering: Applications and Practice, 2, 1, 3544.

Wang, G.; Huang, S. H. and Dismukes, J. P. (2004). Product-driven supply chain selection using integrated multicriteria decision-making methodology. International Journal of Production Economics, 91, 1-15.

Yang, T. and Kuo, C. (2003). A hierarchical AHP/DEA methodology for the facilities layout design problem. European Journal of Operational Research, 147, 128-136. 
Akalin et al. /International Journal of Research in Business and Social Sciences Vol 2, No 4, 2013. ISSN: 2147-4478

Yun, J. (2004). Model for measuring Korean administrative corruption: focusing on the application of the AHP method. International Area Studies Review, 7, 221-245. 
APPENDIX A. Pairwise comparison judgment matrix and weights for the criteria and attributes

A1. Pairwise comparison judgment matrix and weights with respect to the goal 'Selection Criteria of Retail Store Location'

\begin{tabular}{|c|c|c|c|c|c|}
\hline Goal: Selection Criteria of Retail Store Location & C1 & $\mathrm{C2}$ & $\mathbf{C 3}$ & $\mathbf{C 4}$ & $\begin{array}{l}\text { Relative } \\
\text { weights }\end{array}$ \\
\hline - $\quad$ Population $(\mathrm{C} 1)$ & 1 & 4 & 5 & 3 & 0.526 \\
\hline - $\quad$ Retail Settlement $(\mathrm{C} 2)$ & & 1 & 2 & 0.33 & 0.124 \\
\hline - $\quad$ Costs $(\mathrm{C} 3)$ & & & 1 & 0.25 & 0.077 \\
\hline - $\quad$ Competition (C4) & & & & 1 & 0.272 \\
\hline
\end{tabular}

A2. Pairwise comparison judgment matrix and weights with respect to the criteria 'Population'

\begin{tabular}{|c|c|c|c|c|}
\hline Attributes of Population & C5 & C6 & C7 & $\begin{array}{l}\text { Relative } \\
\text { weights }\end{array}$ \\
\hline $\begin{array}{l}\text { - The amount of money that people are willing to spend for buying the retailers' goods } \\
\text { (C5) }\end{array}$ & 1 & 2 & 0.50 & 0.214 \\
\hline - $\quad$ Population growth rate $(\mathrm{C} 6)$ & & 1 & 0.25 & 0.107 \\
\hline - $\quad$ Coherent target market (gender, education, age, occupation etc.) (C7) & & & 1 & 0.429 \\
\hline
\end{tabular}

A3. Pairwise comparison judgment matrix and weights with respect to the criteria 'Retail Settlement'

\begin{tabular}{|c|c|c|c|c|}
\hline Attributes of Retail Settlement & C8 & C9 & $\mathrm{C10}$ & $\begin{array}{c}\text { Relative } \\
\text { weights }\end{array}$ \\
\hline Parking facilities (C8) & 1 & 0.25 & 0.50 & 0.107 \\
\hline - Corner location or located near road intersection (C9) & & 1 & 2 & 0.420 \\
\hline - $\quad$ Ease in accessibility $(\mathrm{C} 10)$ & & & 1 & 0.214 \\
\hline
\end{tabular}

A4. Pairwise comparison judgment matrix and weights with respect to the criteria 'Costs'

\begin{tabular}{|c|c|c|c|c|}
\hline Attributes of Costs & C13 & C14 & C15 & $\begin{array}{l}\text { Relative } \\
\text { weights }\end{array}$ \\
\hline - $\quad$ Building and/or renovating costs (C11) & 1 & 0.33 & 2 & 0.172 \\
\hline - Buying or renting costs $(\mathrm{C} 12)$ & & 1 & 5 & 0.486 \\
\hline - Transportation and/ or warehousing costs (C13) & & & 1 & 0.092 \\
\hline
\end{tabular}

A5. Pairwise comparison judgment matrix and relative weights with respect to the criteria 'Competition'

\begin{tabular}{|c|c|c|c|c|c|}
\hline Attributes of Competition & C16 & C17 & C18 & C19 & $\begin{array}{l}\text { Relative } \\
\text { weights }\end{array}$ \\
\hline Competitors' store numbers (C14) & 1 & 1 & 3 & 1 & 0.450 \\
\hline - The spatial proximity to competitors $(\mathrm{C} 15)$ & & 1 & 3 & 1 & 0.300 \\
\hline - Closeness to culture, amusement and relaxation centers (C16) & & & 1 & 0.33 & 0.099 \\
\hline - $\quad$ Travel time $(\mathrm{C} 17)$ & & & & 1 & 0.300 \\
\hline
\end{tabular}


APPENDIX B. Pairwise comparison judgment matrix and weights for alternatives with respect to the attributes B1. Pairwise comparison judgment matrix and weights for alternatives with respect to the criteria 'Population'

\begin{tabular}{|c|c|c|c|c|}
\hline & \multicolumn{4}{|c|}{ Population } \\
\hline & A1 & A2 & A3 & $\begin{array}{l}\text { Relative } \\
\text { weights }\end{array}$ \\
\hline UMRANIYE (A1) & 1 & 1 & 5 & 0.350 \\
\hline ESKISEHIR MERKEZ (A2) & & 1 & 4 & 0.325 \\
\hline BODRUM (A3) & & & 1 & 0.075 \\
\hline
\end{tabular}

B2. Pairwise comparison judgment matrix and weights for alternatives with respect to the criteria 'Retail Settlement'

\begin{tabular}{lccc}
\hline & & \multicolumn{2}{c}{ Retail Settlement } \\
\hline & A1 & A2 & A3 \\
weights & 1 & 2 & 5 \\
ESKISEHIR MERKEZ (A2) & & 1 & 3 \\
BODRUM (A3) & & 0.436 \\
\hline Consistency ratio & 0.001 & 0.082 \\
\end{tabular}

B3. Pairwise comparison judgment matrix and weights for alternatives with respect to the criteria 'Costs'

\begin{tabular}{|c|c|c|c|c|}
\hline & \multicolumn{4}{|c|}{ Costs } \\
\hline & A1 & A2 & $\mathbf{A 3}$ & $\begin{array}{l}\text { Relative } \\
\text { weights }\end{array}$ \\
\hline UMRANIYE (A1) & 1 & 3 & 5 & 0.486 \\
\hline ESKISEHIR MERKEZ (A2) & & 1 & 2 & 0.172 \\
\hline BODRUM (A3) & & & 1 & 0.092 \\
\hline
\end{tabular}

B4. Pairwise comparison judgment matrix and weights for alternatives with respect to the criteria 'Competition'

\begin{tabular}{|c|c|c|c|c|}
\hline & \multicolumn{4}{|c|}{ Competition } \\
\hline & $\mathbf{A 1}$ & A2 & A3 & $\begin{array}{c}\text { Relative } \\
\text { weights }\end{array}$ \\
\hline UMRANIYE (A1) & 1 & 1 & 4 & 0.343 \\
\hline $\begin{array}{l}\text { ESKISEHIR } \\
\text { MERKEZ (A2) }\end{array}$ & & 1 & 3 & 0.312 \\
\hline BODRUM (A3) & & & 1 & 0.094 \\
\hline Consistency ratio & 0.005 & & & \\
\hline
\end{tabular}

B5. Pairwise comparison judgment matrix and weights for alternatives with respect to the attributes of 'Population'

\begin{tabular}{|c|c|c|c|c|c|c|c|c|c|c|c|c|}
\hline & \multicolumn{4}{|c|}{$\begin{array}{l}\text { The amount of money that } \\
\text { people are willing to spend } \\
\text { for buying the retailers' goods }\end{array}$} & \multicolumn{4}{|c|}{ Population growth rate } & \multicolumn{4}{|c|}{ Coherent target market } \\
\hline & A1 & A2 & A3 & $\begin{array}{l}\text { Relative } \\
\text { weights }\end{array}$ & A1 & A2 & A3 & $\begin{array}{l}\text { Relative } \\
\text { weights }\end{array}$ & A1 & A2 & $\mathbf{A 3}$ & $\begin{array}{l}\text { Relative } \\
\text { weights }\end{array}$ \\
\hline UMRANIYE (A1) & 1 & 0.50 & 3 & 0.232 & 1 & 2 & 5 & 0.436 & 1 & 1 & 5 & 0.341 \\
\hline $\begin{array}{l}\text { ESKISEHIR } \\
\text { MERKEZ (A2) }\end{array}$ & & 1 & 5 & 0.436 & & 1 & 3 & 0.232 & & 1 & 5 & 0.341 \\
\hline BODRUM (A3) & & & 1 & 0.082 & & & 1 & 0.082 & & & 1 & 0.068 \\
\hline Consistency ratio & 0.001 & & & & 0.001 & & & & 0.000 & & & \\
\hline
\end{tabular}


B6. Pairwise comparison judgment matrix and weights for alternatives with respect to the attributes of 'Retail Settlement'

\begin{tabular}{|c|c|c|c|c|c|c|c|c|c|c|c|c|}
\hline & \multicolumn{4}{|c|}{ Parking facilities } & \multicolumn{4}{|c|}{$\begin{array}{l}\text { Corner location or } \\
\text { located near road intersection }\end{array}$} & \multicolumn{4}{|c|}{ Ease in accessibility } \\
\hline & A1 & A2 & $\mathbf{A 3}$ & $\begin{array}{l}\text { Relative } \\
\text { weights }\end{array}$ & A1 & A2 & $\mathbf{A 3}$ & $\begin{array}{l}\text { Relative } \\
\text { weights }\end{array}$ & A1 & A2 & $\mathbf{A 3}$ & $\begin{array}{l}\text { Relative } \\
\text { weights }\end{array}$ \\
\hline UMRANİYE (A1) & 1 & 1 & 1 & 0.250 & 1 & 4 & 5 & 0.511 & 1 & 0.50 & 0.250 & 0.100 \\
\hline $\begin{array}{l}\text { ESKISEHIR } \\
\text { MERKEZ (A2) }\end{array}$ & & 1 & 1 & 0.250 & & 1 & 2 & 0.151 & & 1 & 0.250 & 0.158 \\
\hline BODRUM (A3) & & & 1 & 0.250 & & & 1 & 0.088 & & & 1 & 0.491 \\
\hline Consistency ratio & 0.000 & & & & 0.021 & & & & 0.047 & & & \\
\hline
\end{tabular}

B7. Pairwise comparison judgment matrix and weights for alternatives with respect to the attributes of 'Costs'

\begin{tabular}{|c|c|c|c|c|c|c|c|c|c|c|c|c|}
\hline & \multicolumn{4}{|c|}{ Building and/or renovating costs } & \multicolumn{4}{|c|}{ Buying or renting costs } & \multicolumn{4}{|c|}{$\begin{array}{l}\text { Transportation and/ or } \\
\text { warehousing costs }\end{array}$} \\
\hline & A1 & $\mathbf{A 2}$ & $\mathbf{A 3}$ & Relative weights & A1 & $\mathbf{A 2}$ & $\mathbf{A 3}$ & Relative weights & A1 & $\mathbf{A 2}$ & $\mathbf{A 3}$ & $\begin{array}{l}\text { Relative } \\
\text { weights }\end{array}$ \\
\hline UMRANIYE (A1) & 1 & 0.50 & 3 & 0.232 & 1 & 0.33 & 2 & 0.172 & 1 & 3 & 5 & 0.486 \\
\hline $\begin{array}{l}\text { ESKISEHIR } \\
\text { MERKEZ (A2) }\end{array}$ & & 1 & 5 & 0.436 & & 1 & 5 & 0.486 & & 1 & 2 & 0.172 \\
\hline BODRUM (A3) & & & 1 & 0.082 & & & 1 & 0.367 & & & 1 & 0.092 \\
\hline Consistency ratio & 0.001 & & & & 0.001 & & & & 0.001 & & & \\
\hline
\end{tabular}

B8. Pairwise comparison judgment matrix and weights for alternatives with respect to the attributes of 'Competition'

\begin{tabular}{|c|c|c|c|c|c|c|c|c|c|c|c|c|c|c|c|c|}
\hline & \multicolumn{4}{|c|}{$\begin{array}{l}\text { Competitors' } \\
\text { store numbers }\end{array}$} & \multicolumn{4}{|c|}{$\begin{array}{l}\text { The spatial proximity } \\
\text { to competitors }\end{array}$} & \multicolumn{4}{|c|}{$\begin{array}{l}\text { Closeness to culture, } \\
\text { amusement and } \\
\text { relaxation centers }\end{array}$} & \multicolumn{3}{|c|}{ Travel time } & \multirow[b]{2}{*}{$\begin{array}{c}\text { Relative } \\
\text { weights }\end{array}$} \\
\hline & $\mathbf{A 1}$ & $\mathbf{A 2}$ & $\mathbf{A 3}$ & $\begin{array}{c}\text { Relative } \\
\text { weights }\end{array}$ & A1 & A2 & $\mathbf{A 3}$ & $\begin{array}{c}\text { Relative } \\
\text { weights }\end{array}$ & A1 & A2 & $\mathbf{A} 3$ & $\begin{array}{c}\text { Relative } \\
\text { weights }\end{array}$ & A1 & A2 & $\mathbf{A 3}$ & \\
\hline $\begin{array}{l}\text { UMRANIYE } \\
\text { (A1) } \\
\text { ESKISEHIR }\end{array}$ & 1 & 2 & 5 & 0.436 & 1 & 4 & 5 & 0.510 & 1 & 1 & 4 & 0.343 & 1 & 0.50 & 0.20 & 0.092 \\
\hline $\begin{array}{l}\text { MERKEZ } \\
(\mathrm{A} 2)\end{array}$ & & 1 & 3 & 0.232 & & 1 & 2 & 0.151 & & 1 & 3 & 0.312 & & 1 & 0.33 & 0.172 \\
\hline $\begin{array}{l}\text { BODRUM } \\
\text { (A3) }\end{array}$ & & & 1 & 0.082 & & & 1 & 0.088 & & & 1 & 0.094 & & & 1 & 0.486 \\
\hline $\begin{array}{l}\text { Consistency } \\
\text { ratio }\end{array}$ & 0.001 & & & & 0.022 & & & & 0.005 & & & & 0.001 & & & \\
\hline
\end{tabular}

